\title{
Implementing Automated Triggers to Identify Hospitalized Patients with Possible Unmet Palliative Needs: Assessing the Impact of This Systems Approach on Clinicians
}

\author{
Jeffrey L. Greenwald, MD, ${ }^{1}$ Joseph A. Greer, $\mathrm{PhD}{ }^{2}$ Denisa Gace, DO, MPH, ${ }^{3}$ \\ Robert K. Sommer, BS, ${ }^{2}$ Bethany-Rose Daubman, MD, ${ }^{4}$ Leah B. Rosenberg, MD, ${ }^{4}$ \\ Cynthia LaSala, MS, RN, ${ }^{5}$ and Juliet Jacobsen, $\mathrm{MD}^{4}$
}

\begin{abstract}
Background: Understanding patients' goals and values is important to ensure goal-concordant care; however, such discussions can be challenging. Little is known about the impact of having these discussions on hospitalists.

Objective: To assess the impact on hospitalists of a system that reminds them to have serious illness conversations with their patients identified with potential unmet palliative needs.

Design: Two group cohort trial.

Setting/Subjects: Single academic center. Internal medicine hospitalist physicians, nurse practitioners, and physician's assistants.

Measurements: Before the trial, all participants received serious illness conversation training. During the trial, hospitalists on intervention units received verbal notification when their recently admitted patients were identified using a computer algorithm as having possible unmet palliative needs. Hospitalists on the control unit received no notifications. At baseline and three months, hospitalists completed questionnaires regarding communication skill acquisition, perception of the importance of these conversations, and sense of the meaning gained from having them.

Results: Both groups had similar improvements in their self-reported communication skills and experienced a small decline in how important they felt the conversations were. Neither group perceived having the discussions as being affectively harmful to patients. The intervention hospitalists, over time, reported a slight reduction in the sense of meaning they achieved from the conversations.

Conclusion: Routinely informing hospitalists when their patients were identified as being at increased risk for unmet palliative needs did not increase the sense of meaning these providers achieved. It is likely the pretrial training accounted for many of the positive outcomes in communication skills observed in both arms of the trial.
\end{abstract}

Keywords: clinician experience; hospital medicine; physician patient communication; primary palliative care; serious illness conversation

\footnotetext{
${ }^{1}$ Core Educator Faculty, Department of Medicine, Massachusetts General Hospital, Boston, Massachusetts, USA.

${ }^{2}$ Center for Psychiatric Oncology and Behavioral Sciences, Department of Psychiatry, Massachusetts General Hospital, Boston, Massachusetts, USA.

${ }^{3}$ Hospital Medicine Unit, Department of Medicine, Massachusetts General Hospital, Boston, Massachusetts, USA.

${ }^{4}$ Division of Palliative Care and Geriatric Medicine, Department of Medicine, Massachusetts General Hospital, Boston, Massachusetts, USA.

${ }^{5}$ Department of Nursing, Massachusetts General Hospital, Boston, Massachusetts, USA.

Accepted May 12, 2020.
} 


\section{Introduction}

O ARE BY SPECIALIST palliative care providers has been shown to improve quality of life, reduce symptom burden, and, in some studies, lengthen survival of seriously ill patients. ${ }^{1}$ There may also be an associated cost savings to engaging palliative care specialists with certain patient populations. ${ }^{2,3}$ Despite these benefits, there is a national shortage of specialty palliative care providers. ${ }^{4,5}$ Hospitalists, often the frontline providers for seriously ill patients, are optimally positioned to deliver generalist palliative care, thereby potentially impacting patient outcomes and health care utilization. In fact, a core competency for hospitalists from the Society of Hospital Medicine is the ability to lead culturally sensitive communications about prognosis and goals of care among patients, families, and other members of the health care team. ${ }^{6}$

Communication with patients facing serious illness can be challenging for hospitalists. A recent study identified several barriers hospitalists commonly encounter when engaging in primary palliative care communication, including lack of time, uncertainty around prognosis, complicated patient and family dynamics, and difficulty locating prior documentation of goals and values conversations. ${ }^{7}$ For some providers such conversations may be emotionally draining or uncomfortable, ${ }^{8-10}$ which leads to avoidance. For others, however, these interactions confer deep meaning to their clinical work. ${ }^{11}$ Notably, an inadequate sense of meaning in one's work has been identified as a significant contributor to physician burnout. ${ }^{12}$

Given these potential barriers, a systems-based approach might help hospitalists gain enhanced communication skills and confidence while increasing their sense of the importance of these conversations. Systems-based reminders have been used in many clinical arenas to prompt clinicians and patients to perform desired tasks. Such reminders, however, have shown mixed results in terms of their impact on the desired outcomes. $^{13,14}$

In this study, we studied hospitalists who had undergone prior training in conducting Serious Illness Conversations (SICs) ${ }^{15}$ and utilized an electronic health record algorithm to identify patients with a high likelihood of unmet palliative care needs. We examined the impact of informing clinicians that their hospitalized patients had been identified by the algorithm. We hypothesized that this trigger approach would lead clinicians to recognize the need for and benefits of communicating with patients about their serious illness and that clinicians would experience an enhanced sense of skill, value, and meaning around these patient interactions.

\section{Methods}

\section{Setting}

As previously described, the study was conducted at Massachusetts General Hospital, a teaching affiliate of Harvard Medical School. The study took place on general medical inpatient units designated as control or intervention units that were staffed by attending hospitalist physicians, nurse practitioners (NPs), and physician assistants (PAs) who work as direct care providers. The providers on the intervention units were cohorted such that they predominantly worked on these units or other units not involved in the study during the study period. Similarly, providers on the control units largely worked on control units or on nonstudy units.

\section{Study sample}

As part of a hospital medicine-wide quality improvement effort, all hospital medicine physicians, NPs, and PAs were trained in the Serious Illness Care Program (SICP). ${ }^{15}$ After completing SICP training, participation in the study was voluntary and consent was obtained. We excluded clinicians who worked exclusively at night and would thus not have experienced the intervention that occurred during the day $(N=4)$ and those who received SICP training but never rotated on the intervention or control units during the study period $(N=8)$. All other physicians, NPs, and PAs who rotated on the study units were eligible for enrollment.

\section{Intervention and control}

Upon enrollment, all clinicians were asked to complete baseline, self-report measures, including a demographic questionnaire, information about their clinical experience, and a survey that assessed clinician confidence about communicating with patients about serious illness and perceptions regarding the impact that such conversations have on patients and themselves. The clinician survey was adapted from prior studies of the SICP in both primary care and longterm acute hospital settings. ${ }^{16,17}$

Thereafter, each morning, a research assistant (RA) reviewed the recent admissions to the study units to identify patients who triggered our previously described internally developed automated screening tool created to identify patients who were at risk for unmet palliative needs. On intervention units, during morning interprofessional rounds, the RA would inform clinicians that the patient had been identified as possibly having unmet palliative needs and recommend that the clinician consider initiating a serious illness conversation, if appropriate. On the control unit, the RA would screen recent admissions similarly, but this information was not shared with clinicians.

Approximately three months after enrollment, the clinicians were asked to repeat the same surveys as on enrollment to assess their confidence with having serious illness conversations and the personal and professional impact these conversations have.

\section{Data analysis plan}

We conducted all statistical analyses using SPSS (IBM Statistical Package for Social Sciences, v.21), first tabulating frequencies, means, and standard deviations for the baseline characteristics of the clinician sample. We used independentsamples $t$ tests and chi-square tests to explore any differences in baseline characteristics between clinicians on the intervention versus control inpatients units. To examine change over time within each study group as well as differences between those on the intervention and the control inpatient units, we calculated analysis of covariance (ANCOVA) models with inpatient unit as the independent variable (i.e., control vs. intervention) and change scores for each clinicianreported outcome measure as the dependent variable (followup minus baseline). All models were adjusted for baseline values of the respective outcome measure.

This study was approved by the Partners Institutional Review Board. 
Table 1. Clinician Baseline Characteristics

\begin{tabular}{lcccc}
\hline & Full cohort, $\mathrm{N}=61$ & Control unit, $\mathrm{N}=23$ & Intervention unit, $\mathrm{N}=38$ & $\mathrm{p}$ \\
\hline Age, mean (SD) & $33.80(7.12)$ & $34.91(7.98)$ & $33.16(6.60)$ & 0.363 \\
Gender, $N(\%)$ & $31(50.8)$ & $11(47.8)$ & $20(52.6)$ & 0.795 \\
$\quad$ Woman & $30(49.2)$ & $12(52.2)$ & $18(47.4)$ & \\
$\quad$ Man & $44(72.1)$ & $20(87.0)$ & $24(63.2)$ & 0.075 \\
Professional role, $N(\%)$ & $17(27.9)$ & $3(13.0)$ & $14(36.8)$ & \\
$\quad$ MD/DO & $3.75(4.80)$ & $4.39(5.23)$ & $3.36(4.55)$ & 0.422 \\
$\quad$ NP/PA & & &
\end{tabular}

NP, nurse practitioner; PA, physician assistant; SD, standard deviation.

\section{Results}

We approached and enrolled 73 of 87 eligible hospitalists for this study (84\%). At baseline, 73 hospital medicine clinicians completed the self-report measures, of whom 12 were excluded from this analysis due to not rotating on the study units $(n=8)$ or only working the overnight shift $(n=4)$. The remaining 61 clinicians (control $N=23$; intervention $N=38$ ) had evaluable data at baseline, and 39 clinicians (64\%) completed the follow-up self-report measures (control $N=13$; intervention $N=26$ ). The clinicians with missing follow-up data did not differ significantly in any baseline characteristic compared with those who completed the self-report measures at both time points. As shown in Table 1, the clinicians were predominantly physicians, largely young (mean age: 33.8 ) and early in their career (mean years in practice: 3.75 ), with approximately equal numbers of women and men.

From baseline to follow-up assessment, clinicians in both study groups reported increased confidence in certain aspects of their serious illness communication with patients (Table 2). Specifically, clinicians on the intervention units demonstrated a statistically significant increase in confidence on 9 of the 10

Table 2. Within- and Between-Group Differences in Clinician-Reported Confidence in Serious Illness Communication with Patients

\begin{tabular}{|c|c|c|c|c|c|c|}
\hline & \multicolumn{2}{|c|}{$\begin{array}{l}\text { Control unit }(\mathrm{N}=13) \\
\text { within-group change } \\
\text { over time }\end{array}$} & \multicolumn{2}{|c|}{$\begin{array}{c}\text { Intervention unit }(\mathrm{N}=26) \\
\text { within-group change } \\
\text { over time }\end{array}$} & \multicolumn{2}{|l|}{$\begin{array}{l}\text { Between-group } \\
\text { mean differences }\end{array}$} \\
\hline & $\begin{array}{c}\text { Mean } \\
\text { change (SE) }\end{array}$ & $95 \% C I$ & $\begin{array}{c}\text { Mean } \\
\text { change (SE) }\end{array}$ & $95 \% C I$ & $\begin{array}{l}\text { Mean difference } \\
\quad(95 \% \mathrm{CI})\end{array}$ & $\mathrm{p}$ \\
\hline $\begin{array}{l}\text { Demonstrating empathy toward } \\
\text { my patient }\end{array}$ & $0.10(0.24)$ & -0.38 to 0.58 & $0.26(0.17)$ & -0.08 to 0.60 & $0.16(-0.43$ to 0.75$)$ & 0.580 \\
\hline $\begin{array}{l}\text { Responding to my patient's } \\
\text { emotions }\end{array}$ & $0.60(0.19)^{\mathrm{a}}$ & 0.21 to 0.99 & $0.55(0.14)^{\mathrm{a}}$ & 0.27 to 0.82 & $-0.05(-0.53$ to 0.43$)$ & 0.825 \\
\hline $\begin{array}{l}\text { Exploring my patient's hopes } \\
\text { about his/her health }\end{array}$ & $0.42(0.24)$ & -0.07 to 0.92 & $0.71(0.17)^{\mathrm{a}}$ & 0.36 to 1.06 & $0.29(-0.32$ to 0.90$)$ & 0.341 \\
\hline $\begin{array}{l}\text { Exploring my patient's worries } \\
\text { about his/her health }\end{array}$ & $0.50(0.25)$ & -0.01 to 1.00 & $0.75(0.18)^{\mathrm{a}}$ & 0.39 to 1.11 & $0.26(-0.37$ to 0.88$)$ & 0.412 \\
\hline $\begin{array}{l}\text { Assessing my patient's } \\
\text { prognostic awareness }\end{array}$ & $0.58(0.27)^{\mathrm{a}}$ & 0.03 to 1.13 & $0.86(0.19)^{\mathrm{a}}$ & 0.48 to 1.25 & $0.28(-0.39$ to 0.96$)$ & 0.400 \\
\hline $\begin{array}{l}\text { Managing prognostic uncertainty } \\
\text { with my patient }\end{array}$ & $0.97(0.24)^{\mathrm{a}}$ & 0.48 to 1.46 & $1.09(0.17)^{\mathrm{a}}$ & 0.75 to 1.44 & $0.12(-0.48$ to 0.73$)$ & 0.680 \\
\hline $\begin{array}{l}\text { Delivering prognostic } \\
\text { information to my patient }\end{array}$ & $0.41(0.20)$ & -0.01 to 0.82 & $0.61(0.14)^{\mathrm{a}}$ & 0.31 to 0.90 & $0.20(-0.31$ to 0.70$)$ & 0.430 \\
\hline $\begin{array}{l}\text { Eliciting what is important to my } \\
\text { patient given his/her current } \\
\text { health status }\end{array}$ & $0.39(0.22)$ & -0.04 to 0.83 & $0.73(0.15)^{\mathrm{a}}$ & 0.42 to 1.04 & $0.33(-0.20$ to 0.87$)$ & 0.213 \\
\hline $\begin{array}{l}\text { Exploring how much my patient } \\
\text { has spoken with loved ones } \\
\text { about his/her health }\end{array}$ & $0.86(0.24)^{\mathrm{a}}$ & 0.37 to 1.36 & $0.84(0.17)^{\mathrm{a}}$ & 0.49 to 1.19 & $-0.02(-0.63$ to 0.59$)$ & 0.942 \\
\hline $\begin{array}{l}\text { Collaborating with my team to } \\
\text { have serious illness } \\
\text { conversations with my patient }\end{array}$ & $0.43(0.25)$ & -0.07 to 0.93 & $0.71(0.17)^{\mathrm{a}}$ & 0.36 to 1.06 & $0.28(-0.33$ to 0.90$)$ & 0.359 \\
\hline
\end{tabular}

Values represent within- and between-group changes in clinician-reported confidence in each area ranging from 1 (not confident) to 7 (very confident). Positive mean change scores within each study group indicate increased clinician-reported confidence over time.

${ }^{a} p<0.05$; results in table derived from ANCOVA models adjusted for baseline scores of criterion outcome variables. ANCOVA, analysis of covariance. 
Table 3. Within- and Between-Group Differences in Clinician Communication During Most Recent Serious Illness Conversation

\begin{tabular}{|c|c|c|c|c|c|c|}
\hline & \multicolumn{2}{|c|}{$\begin{array}{l}\text { Control unit }(\mathrm{N}=13) \\
\text { within-group change } \\
\text { over time }\end{array}$} & \multicolumn{2}{|c|}{$\begin{array}{c}\text { Intervention unit }(N=26) \\
\text { within-group change } \\
\text { over time }\end{array}$} & \multicolumn{2}{|l|}{$\begin{array}{l}\text { Between-group } \\
\text { mean differences }\end{array}$} \\
\hline & $\begin{array}{c}\text { Mean } \\
\text { change (SE) }\end{array}$ & $95 \% C I$ & $\begin{array}{c}\text { Mean } \\
\text { change (SE) }\end{array}$ & $95 \% C I$ & $\begin{array}{l}\text { Mean difference } \\
(95 \% \mathrm{CI})\end{array}$ & $\mathrm{p}$ \\
\hline $\begin{array}{l}\text { To what extent did you evaluate } \\
\text { your patient's prognostic } \\
\text { awareness? }\end{array}$ & $0.23(0.21)$ & -0.19 to 0.65 & $0.04(0.15)$ & -0.26 to 0.34 & $-0.19(-0.71$ to 0.33$)$ & 0.465 \\
\hline $\begin{array}{l}\text { To what extent did you } \\
\text { understand your patient's } \\
\text { preferences regarding sharing } \\
\text { of information with family } \\
\text { member(s)? }\end{array}$ & $0.68(0.24)^{\mathrm{a}}$ & 0.20 to 1.16 & $0.12(0.17)$ & -0.22 to 0.46 & $-0.56(-1.16$ to 0.04$)$ & 0.065 \\
\hline $\begin{array}{l}\text { To what extent did you ask about } \\
\text { your patient's life goals? }\end{array}$ & $-0.03(0.27)$ & -0.57 to 0.51 & $0.40(0.19)^{\mathrm{a}}$ & 0.02 to 0.78 & $0.43(-0.23$ to 1.09$)$ & 0.197 \\
\hline $\begin{array}{l}\text { To what extent did you ask about } \\
\text { your patient's fears and } \\
\text { worries? }\end{array}$ & $0.73(0.21)^{\mathrm{a}}$ & 0.30 to 1.17 & $0.79(0.15)^{\mathrm{a}}$ & 0.48 to 1.09 & $0.05(-0.48$ to 0.58$)$ & 0.841 \\
\hline $\begin{array}{l}\text { Overall, how effective was this } \\
\text { discussion in understanding } \\
\text { your patient's values and goals } \\
\text { about end-of-life care? }\end{array}$ & $0.05(0.26)$ & -0.48 to 0.58 & $0.44(0.19)^{\mathrm{a}}$ & 0.06 to 0.81 & $0.39(-0.26$ to 1.04$)$ & 0.236 \\
\hline
\end{tabular}

Values represent within- and between-group changes in clinician-reported confidence in each area ranging from 1 (not at all) to 5 (a great deal). Positive mean change scores within each study group indicate increased clinician-reported engagement on serious illness conversation.

${ }^{\mathrm{a}} p<0.05$; results in table derived from ANCOVA models adjusted for baseline scores of criterion outcome variables

serious illness communication measures, whereas clinicians on the control units reported a significant increase in 4 of the 10 measures. Nonetheless, the mean between-group change in clinician-reported confidence in their serious illness communication did not differ significantly between study groups across any of these measures.

When specifically asked to recall and rate their last serious illness conversation with a patient, the clinicians in both study groups reported a similar pattern noting improved communication along certain domains (e.g., asking about your patient's fears and worries) but not others (e.g., evaluating patient's prognostic awareness). None of the improvements in clinician communication from baseline to follow-up assessment within each study group differed significantly between those on the intervention versus control units (Table 3).

From baseline to follow-up assessment, clinicians in both groups reported a perception that having a serious illness conversation did not have a negative impact on the emotional state of patients (Table 4). Both groups also noted a similar decline from the start of the study to the follow-up survey in their perceived sense of the importance of having serious illness conversations with patients and families (control $3.50-3.17$ out of 4 ; intervention 3.50-3.23 out of $4 ; p<0.05$ for both). Clinicians on the intervention units noted an increased frequency of seeking coaching from a colleague in preparation for holding SICs, whereas the control group noted a slight drop. Despite this change, although both groups noted that having these conversations was meaningful to their work, clinicians on the intervention units reported a relative decrease in this perception over time, with Likert scores dropping from 4.35 to $4.08(p<0.05)$, a drop not seen in the control group (4.31-4.46; $p=\mathrm{NS})$. Despite these findings, as shown in Figure 1, $>90 \%$ of clinicians in both study groups reported at the baseline and follow-up time points that if they were hospitalized with a serious life-threatening illness, they would want their hospital clinician to have a goals and values discussion with them.

\section{Discussion}

Although hospitalists care for a large proportion of patients with serious illness in the United States, ${ }^{18}$ limited literature exists exploring hospitalists' role in communicating with patients and families about serious illness or the impact that such conversations have on these clinicians. Studies examining communication with patients about serious issues related to their health typically focus on the effect they have on patients. ${ }^{19}$ To our knowledge, this is the first published study examining the impact on hospitalists of informing them that their patients may have unmet palliative needs and may benefit from a goals and values discussion.

Overall, the effect of the intervention on hospitalists was limited. First, although clinicians on the intervention units experienced more growth in confidence around individual advanced communications skills over time, in aggregate, these differences were not significantly different from the growth noted among the clinicians on the control units. Second, nearly all clinicians in both groups stated they would want a goals and values discussion for themselves if they were patients. Third, both groups experienced a small decrement in their perception of the importance of holding serious illness conversations. Finally, although both groups endorsed experiencing a moderately strong sense of meaning from having these conversations, clinicians on the intervention units demonstrated a small 
Table 4. Within- and Between-Group Differences in Clinician Perceptions of Serious Illness CONVERSATIONS With Patients

\begin{tabular}{|c|c|c|c|c|c|c|}
\hline & \multicolumn{2}{|c|}{$\begin{array}{l}\text { Control unit }(\mathrm{N}=13) \\
\text { within-group change } \\
\text { over time }\end{array}$} & \multicolumn{2}{|c|}{$\begin{array}{c}\text { Intervention unit }(\mathrm{N}=26) \\
\text { within-group change } \\
\text { over time }\end{array}$} & \multicolumn{2}{|l|}{$\begin{array}{l}\text { Between-group } \\
\text { mean differences }\end{array}$} \\
\hline & $\begin{array}{c}\text { Mean } \\
\text { change }(S E)\end{array}$ & $95 \% C I$ & $\begin{array}{c}\text { Mean } \\
\text { change (SE) }\end{array}$ & $95 \% C I$ & $\begin{array}{l}\text { Mean difference } \\
(95 \% \mathrm{CI})\end{array}$ & $\mathrm{p}$ \\
\hline $\begin{array}{l}\text { How serious illness } \\
\text { conversation affected } \\
\text { patient's emotional state }\end{array}$ & $0.30(0.26)$ & -0.22 to 0.82 & $0.31(0.18)$ & -0.06 to 0.68 & $0.01(-0.62$ to 0.65$)$ & 0.965 \\
\hline $\begin{array}{l}\text { Range: } 1 \text { (much worse) to } 5 \\
\text { (much better) }\end{array}$ & & & & & & \\
\hline $\begin{array}{l}\text { How important it is to have } \\
\text { serious illness } \\
\text { conversations with } \\
\text { patients and families }\end{array}$ & $-0.33(0.15)^{\mathrm{a}}$ & -0.64 to -0.03 & $-0.27(0.10)^{\mathrm{a}}$ & -0.48 to -0.06 & $0.06(-0.31$ to 0.43$)$ & 0.727 \\
\hline $\begin{array}{l}\text { Range: } 1 \text { (not important) to } 4 \\
\text { (extremely important) }\end{array}$ & & & & & & \\
\hline $\begin{array}{l}\text { How much having serious } \\
\text { illness conversations with } \\
\text { patients and families } \\
\text { increases or decreases } \\
\text { clinician's sense of } \\
\text { meaning in their work }\end{array}$ & $0.14(0.16)$ & -0.19 to 0.47 & $-0.26(0.11)^{\mathrm{a}}$ & -0.50 to -0.03 & $-0.40(-0.81$ to -0.001$)$ & 0.050 \\
\hline $\begin{array}{l}\text { Range: } 1 \text { (greatly decrease) } \\
\text { to } 5 \text { (greatly increase) }\end{array}$ & & & & & & \\
\hline $\begin{array}{l}\text { How often clinician engages } \\
\text { patients and families in } \\
\text { serious illness } \\
\text { conversations as part of } \\
\text { standard practice }\end{array}$ & $<0.001(0.19)$ & -0.38 to 0.38 & $0.19(0.13)$ & -0.08 to 0.46 & $0.19(-0.28$ to 0.66$)$ & 0.411 \\
\hline $\begin{array}{l}\text { Range: } 1 \text { (never) to } 5 \text { (all the } \\
\text { time) }\end{array}$ & & & & & & \\
\hline $\begin{array}{l}\text { How often clinician seeks } \\
\text { out coaching support from } \\
\text { another clinician to } \\
\text { prepare for serious illness } \\
\text { conversations with their } \\
\text { patients }\end{array}$ & $-0.57(0.22)^{\mathrm{a}}$ & -1.02 to -0.12 & $0.36(0.16)^{\mathrm{a}}$ & 0.04 to 0.68 & $0.92(0.37$ to 1.48$)$ & 0.002 \\
\hline $\begin{array}{l}\text { Range: } 1 \text { (never) to } 5 \text { (all the } \\
\text { time) }\end{array}$ & & & & & & \\
\hline
\end{tabular}

${ }^{\mathrm{a}} p<0.05$; results in table derived from ANCOVA models adjusted for baseline scores of criterion outcome variables.

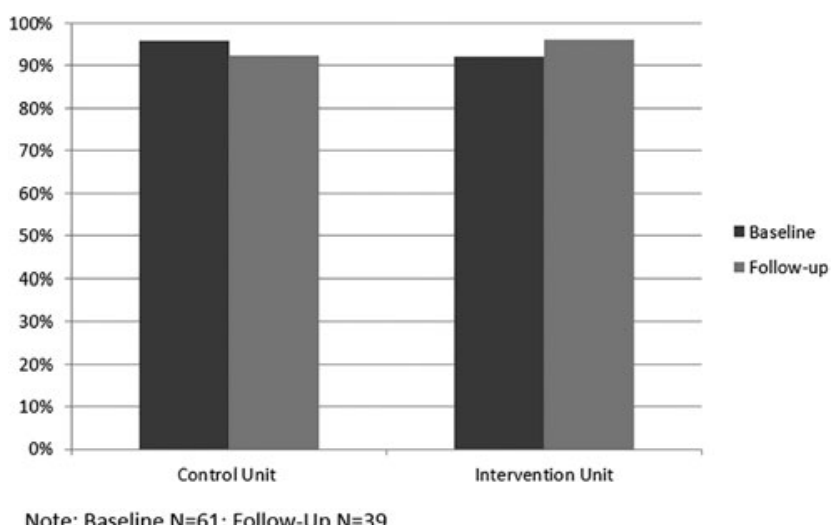

Note: Baseline $\mathrm{N}=61$; Follow-Up $\mathrm{N}=39$

FIG. 1. Clinical report that they would want their hospital clinician to have a values and goals discussion with them if they were hospitalized with a serious or life-threatening illness. decrease in their sense of meaning for the study period. Importantly, both groups perceived no negative effect of having serious illness conversations on patients' mood.

We hypothesize that the changes in confidence observed may have resulted from the reminders ("triggers") being shared at multidisciplinary rounds, provoking additional discussion, which then bolstered confidence for the actual conversations. Why the intervention had little impact on the outcomes associated with their sense of these conversation's importance is likely multifactorial: (1) how busy the hospitalist service is and thus this reminder was perceived as more burdensome than helpful; (2) that the frequency of any individual clinician being triggered was insufficient to create stronger findings; (3) that the initial SIC training inflated these outcomes (i.e., the initial survey results at the start of the study) due to the high quality of the training materials and with time, further experience did not grow these outcomes. Undoubtedly, other contributing factors also existed. 
Why the sense of meaning derived from conversations declined over time is less clear. Notably, both the baseline and follow-up scores assessing the personal sense of meaning of conducting SIC remained $>4$ (Likert scale: 1 being greatly decreased and 5 being greatly increased). Although there was a small decrement in scores over time, the perceived meaning remained positive. Several possible factors may have contributed to this finding: First, as clinicians initiated more conversations, their lack of continuity with patients may have been felt more acutely. Second, there may have been the perception that other clinicians (e.g., specialists or primary care providers) are better positioned to conduct these conversations. Finally, hospitalists may have anticipated a greater sense of meaning from the conversations than they actually experienced. Therefore, this shift in perception may also be due, more broadly, to a change from experiencing this mode of communication as a hypothetical situation, to one that impacts clinicians' "day-to-day" reality.

Clinicians who care for seriously ill patients are often concerned that having discussions about their illness might upset or harm their patients. ${ }^{20,21}$ If conducted poorly, it has been found that failures in clinician communication surrounding serious illness issues can contribute to patients' anxiety and depression, and interventions to improve communication have reduced such symptoms. ${ }^{22-24}$ However, many studies of discussing serious illness-related issues with patients have clearly shown no impact or favorable changes in mood in patients. ${ }^{25}$ Coupled with these studies, this study's demonstrated lack of perceived impact on patient mood reinforces that, with training, clinicians can have these conversations without harming patients or perceiving that they are harming patients. Concerns about causing worsening mood should not be a barrier to conversations.

The clinician experience specifically around meaningmaking is critical to understand as it may be relevant to enhancing job satisfaction. The lack of a sense of meaning in one's work has been identified as a significant contributor to burnout, ${ }^{11}$ an issue that has been of concern in the field of hospital medicine where rates appear to be high. ${ }^{26}$ Thus, continuing to investigate how to support meaning-making during these important patient-centered conversations is crucial.

The results of this study should be considered in light of a number of limitations. First, this was from a single academic institution, making generalizability potentially challenging. Also, not every hospitalist on an intervention unit had a patient identified by the trigger system that may limit the impact identified in the study. In addition, the small sample size (limited by the number of clinicians available on the study units) was further compromised by the attrition of some in our follow-up data, likely causing a lack of sufficient power to observe some possible differences within and between groups. Also, due to the work schedule, we were unable to completely exclude some clinicians crossing over during the study periods between control and intervention units, although all attempts were made to minimize this by a study author (D.G.) who assists with scheduling. The positive impact noted in both arms of the study in many domains may represent the impact of the training program the clinicians underwent before the start of the study and not the automated identification system itself. Finally, the trigger has not been formally validated for this purpose and may not identify the correct population, although previous preliminary audits done internally for quality improvement purposes suggested it performed well, more likely underidentifying patients (i.e., missing cases with unmet palliative needs) rather than overidentifying them (i.e., identifying patients who did not have unmet palliative needs).

\section{Conclusion}

This study demonstrated a limited personal and professional impact of the use of an automated system coupled with a live reminder to identify patients at risk for unmet palliative needs on hospitalists. It appears likely that many of the positive findings identified are more attributable to the training in serious illness conversation skills the clinicians received before the study than the process for identifying patients we put in place. Given the recognized importance of understanding the goals and values of patients and families facing serious illness, further studies of systems aimed at assisting and promoting more routine hospitalist communication in this area, specifically with greater structure and interprofessional approach, are needed. Such future studies should also attend to the impact of serious illness conversations on providers.

\section{Funding Information}

This was an unfunded study.

\section{Author Disclosure Statement}

No competing financial interests exist.

\section{References}

1. Kavalieratos D, Corbelli J, Zhang D, et al.: Association between palliative care and patient and caregiver outcomes: A systematic review and meta-analysis. JAMA 2016;316: 2104-2114.

2. Smith S, Brick A, O'Hara S, Normand C: Evidence of the cost and cost-effectiveness of palliative care: A literature review. Palliat Med 2014;28:130-150.

3. May P, Garrido MM, Cassel JB, et al.: Prospective cohort study of hospital palliative care teams for inpatients with advanced cancer: Earlier consultation is associated with larger cost-saving effect. J Clin Oncol 2015;33:2745-2752.

4. Lupu D. American Academy of Hospice and Palliative Medicine Workforce Task Force: Estimate of current hospice and palliative medicine physician workforce shortage. J Pain Symptom Manage 2010;40:899-911.

5. Spetz J, Dudley N, Trupin L, et al.: Few hospital palliative care programs meet national staffing recommendations. Health Aff 2016;35:1690-1697.

6. Society of Hospital Medicine: Palliative Care. 2017 Hospital Medicine Revised Core Competencies. J Hosp Med 2017;12:S71-S72.

7. Rosenberg LB, Greenwald JL, Caponi B, et al.: Confidence with and barriers to serious illness communication: A National Survey of Hospitalists. J Palliat Med 2017;20:1013-1019.

8. Vanderhaeghen B, Van Beek K, De Prill M, et al.: What do hospitalists experience as barriers and helpful factors for having ACP conversations? A systematic qualitative evidence synthesis. Perspect Public Health 2019;139:97-105.

9. Meier DE, Back AL, Morrison S: The inner life of physicians and care of the seriously ill. JAMA 2001;286:30073014. 
10. Schichtel M, Wee B, MacArtney JI, Collins S: Clinician barriers and faciliatators to heart failure advance care plans: A systematic literature review and qualitative evidence synthesis. BMJ Support Palliat Care 2019. DOI: 10.1136/ bmjspcare-2018-001747.

11. Egnew TR: Suffering, meaning, and healing: Challenges of contemporary medicine. Ann Fam Med 2009;7:170-175.

12. Jager AJ, Tutty MA, Kao AC: Association between physician burnout and identification with medicine as a calling. Mayo Clin Proc 2017;92:415-422.

13. Vervloet M, Linn AJ, van Weert JCM, et al.: The effectiveness of interventions using electronic reminders to improve adherence to chronic medication: A systematic review of the literature. J Am Med Inform Assoc 2012;19: 696-704.

14. El-Kareh RE, Gandhi TK, Poon EG, et al.: Actionable reminders did not improve performance over passive reminders for overdue tests in the primary care setting. J Am Med Inform Assoc 2011;18:160-163.

15. Ariadne Labs: Serious Illness Care. https://www.ariadnelabs .org/areas-of-work/serious-illness-care (Last accessed June 18, 2019.)

16. Lakin JR, Koritsanszky LA, Cunningham R, et al.: A systematic intervention to improve serious illness communication in primary care. Health Aff 2017;36:1258-1264.

17. Lamas DJ, Owens RL, Nace N, et al.: Conversations about goals and values are feasible and acceptable in long-term acute care hospitals: A pilot study. J Palliat Med 2017;20: $710-715$.

18. Anderson WG, Kools S, Lyndon A: Dancing around death: Hospitalist-patient communication about serious illness. Qual Health Res 2013;23:3-13.

19. Tulsky JA, Beach MC, Butow PN, et al.: A research agenda for communication between health care professionals and patients living with serious illness. JAMA Intern Med 2017;177:1361-1366.
20. Fallowfield LJ, Jenkins VA, Beveridge HA: Truth may hurt but deceit hurts more: Communication in palliative care. Palliat Med 2002;16:297-303.

21. Sarafis P, Tsounis A, Malliarou M, Lahana E: Disclosing the truth: A dilemma between instilling hope and respecting patient autonomy in everyday clinical practice. Glob $\mathbf{J}$ Health Sci 2013;6:128.

22. Tilden VP, Tolle SW, Garland MJ, Nelson CA: Decisions about life-sustaining treatment. Impact of physicians' behaviors on the family. Arch Intern Med 1995;155:633-638.

23. Lautrette A, Darmon M, Megarbane B, et al.: A communication strategy and brochure for relatives of patients dying in the ICU. N Engl J Med 2007;356:469-478.

24. Green MJ, Schubart JR, Whitehead MM, et al.: Advance care planning does not adversely affect hope or anxiety among patients with advanced cancer. J Pain Symptom Manage 2015;49:1088-1096.

25. Bernacki RE, Block SD: Communication about serious illness care goals: A review and synthesis of best practices. JAMA Intern Med 2014;174:1994-2003.

26. Medscape Hospitalist Lifestyle, Happiness \& Burnout Report 2019. https://www.medscape.com/slideshow/2019lifestyle-hospitalist-6011430 (Last accessed August 19, 2019).

Address correspondence to: Jeffrey L. Greenwald, MD Core Educator Faculty Department of Medicine Massachusetts General Hospital 50 Staniford Street Suite $503 b$

Boston, MA 02114

USA

E-mail: jlgreenwald@mgh.harvard.edu 